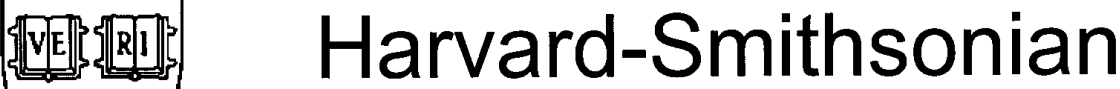 Center for Astrophysics

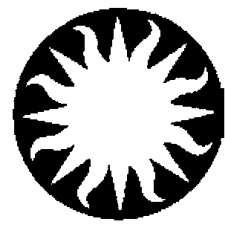

\section{Preprint Series}

No. 4803

(Received June 18, 1999)

\section{MISSION ANALYSIS OF SPINNING SYSTEMS FOR TRANSFERS FROM LOW ORBITS TO GEOSTATIONARY}

E.C. Lorenzini and M.L. Cosmo

Harvard-Smithsonian Center for Astrophysics

M. Kaiser

Technishe Universität München

M.E. Bangham and D.J. Vonderwell

Boeing Defense and Space Group

and

L. Johnson

NASA Marshall Space Flight Center

To appear in

Journal of Spacecraft and Rockets 


\title{
Mission Analysis of Spinning Systems for Transfers from Low Orbits to Geostationary ${ }^{\S}$
}

\author{
E.C. Lorenzini ${ }^{1}$, M.L. Cosmo ${ }^{1}$, M. Kaiser ${ }^{2}$, M.E. Bangham ${ }^{3}$, D.J. Vonderwell ${ }^{3}$ \\ and L. Johnson ${ }^{4}$
}

The paper analyzes the use of spaceborne spinning tethers for a reusable system to transfer payloads with a mass up to $4000 \mathrm{~kg}$ from low orbits to geostationary. The study indicates that a two-stage system is lighter than a single-stage tethered system with present day tether materials. A first stage in low orbit and a second stage in medium Earth orbit provide the required velocity increments for injecting the payload into geotransfer orbit with the final orbit circularization provided by the satellite kick motor. The orbits of the stages are resonant in order to provide periodic encounters and are optimized with the goal of reducing the overall system mass. The close-approach dynamics between the second stage and the payload released from the first stage is simulated to demonstrate the salient features of the rendezvous process. A total of 10 transfers over two years of operation without refueling is adopted for computing the propellant needed to reboost the stages. A preliminary analysis leads to the conclusion that a two-stage tethered system is more competitive, on a mass basis, than a chemical upper stage after two transfers.

\section{Nomenclature}

$$
\begin{array}{ll}
\mathrm{a} & =\text { semimajor axis } \\
\mathrm{e} & =\text { orbital eccentricity or exponential function } \\
\mathrm{E} & =\text { orbital energy } \\
\mathrm{f} & =\text { safety factor } \\
\mathrm{g} & =\text { Earth's gravity acceleration } \\
\mathrm{H} & =\text { altitude above ground } \\
\mathrm{I}_{\mathrm{sp}} & =\text { specific impulse }
\end{array}
$$

\footnotetext{
${ }^{\S}$ Paper presented at the AAS/AIAA Space Flight Mechanics Meeting, Monterey, CA, 9-11 Feb. 1998

${ }^{1}$ Staff Scientist, Radio and Geoastronomy, Harvard-Smithsonian Center for Astrophysics (CfA), 60 Garden Street, MS80, Cambridge, MA 02138, USA

${ }^{2}$ Student, Technishe Universität Munchën, Richard Wagner Strasse 18, 8000 Munich, Germany. Also visiting student of CfA

${ }^{3}$ Aerospace Engineer, Boeing Defense and Space Group, 499 Boeing Blvd., P.O. Box 240002, Huntsville, AL 35824, USA

${ }^{4}$ Program Manager, NASA Marshall Space Flight Center, Mail Code PS02, Huntsville, AL 35812.
} 


$$
\begin{array}{ll}
\mathrm{J}_{2} & =\text { second zonal harmonic of Earth's gravity field } \\
\mathrm{L} & =\text { overall tether length } \\
\mathrm{L}_{\mathrm{ij}} & =\text { distance along tether } \\
\mathrm{l}_{\mathrm{ij}} & =\text { distance along tether } \\
\mathrm{m} & =\text { mass } \\
\mathrm{M} & =\text { ratio between transfer orbit and } 1^{\text {st }} \text { stage orbital periods } \\
\mathrm{N} & =\text { ratio between } 2^{\text {nd }} \text { stage and } 1^{\text {st }} \text { stage orbital periods } \\
\mathrm{P} & =\text { orbital period } \\
\mathrm{r} & =\text { geocentric radius } \\
\mathrm{V} & =\text { velocity } \\
\Delta \mathrm{V} & =\text { velocity increment } \\
\chi & =\text { payload/platform mass ratio } \\
\mu & =\text { Earth's gravitational constant } \\
\omega & =\text { angular speed (rad/s) } \\
\rho & =\text { mass density } \\
\sigma & =\text { ultimate strength } \\
\tau & =\text { tether/platform mass ratio }
\end{array}
$$

Subscript

$$
\begin{array}{ll}
\text { a } & =\text { apogee } \\
\mathrm{c} & =\text { critical } \\
\text { circ } & =\text { circularization } \\
\text { GTO } & =\text { geostationary orbit } \\
\min & =\text { minimum value } \\
\mathrm{p} & =\text { perigee } \\
\text { pay } & =\text { payload } \\
\text { prop } & =\text { propellant } \\
\text { tet } & =\text { tether } \\
\text { tip } & =\text { tether tip } \\
\text { TO } & =\text { transfer orbit } \\
1 & =\text { first stage }(i) \text { or platform }(j) \\
2 & =\text { second stage }(i) \text { or payload }(j)
\end{array}
$$




\section{Introduction}

The scope of this paper is to conduct a system-level mission analysis of a reusable, spinning tethered system for transferring payloads from low Earth orbit (LEO) to geostationary orbit (GEO). The analysis of this paper focuses on the orbital dynamics and the minimization of the overall mass of the transfer system. The system conceptual design and preliminary data about its subsystems are discussed in Ref. 1. The motivation for this study is due to the fact that the projected traffic to GEO is expected to increase ${ }^{2}$ during the next few decades and the cost of delivering payload from the Earth surface to LEO is projected to decrease thanks to the introduction of reusable launching vehicles (RLV). A comparable reduction in upper stages cost must occur in order to deliver payloads to GEO at a fraction of today's expenses.

Consequently, studies for alternatives means of transportation from LEO to GEO have been carried out with the aim at reducing substantially the cost per kilogram transferred to geostationary orbit. Tethers are possible candidates to accomplish this goal because spinning tethers are excellent storage devices of kinetic energy and capable to impart large velocity increments to the payload attached to the tether tip. A tethered system for transferring payload from LEO to GEO with a single stage was first proposed by Bekey ${ }^{3}$. This work capitalizes on that idea and push it a few steps forward.

Spinning tethers are used to impart the desired velocity increments $(\Delta \mathrm{V})$ to the payload to be transferred. Each spinning system has a counter platform (or service module) on the opposite side of the tether. The spinning system acts as a giant momentum wheel, i.e., for each $\Delta \mathrm{V}$ imparted to the payload there is a $\Delta \mathrm{V}$, proportional to the spinning stage mass ratios, imparted to the platform and the tether attached to it. After release, the payload is injected into a higher orbit and the platform is injected into a lower orbit which depends on the mass distribution of the spinning system.

The transfer from LEO to geotransfer orbit (GTO) can be accomplished through a single $\Delta \mathrm{V}$ of about $2.4 \mathrm{~km} / \mathrm{s}$ (from a $300-\mathrm{km}$ circular orbit) provided by a single-stage tethered system or through two smaller $\Delta \mathrm{Vs}$ provided by a two-stage tethered system. This latter configuration is lighter with present day tether technology (as explained later on). A two-stage tethered system involves two facilities permanently in orbit (see Fig. 1): a spinning facility in LEO and another one in medium Earth orbit (MEO) with a perigee 
close to the LEO facility. The two stages are in equatorial orbits. The payload is first boosted with a velocity increment $\Delta \mathrm{V}_{1}$ to MEO from the LEO facility. The payload is, then, captured (with zero relative velocity) at perigee by the MEO facility and at a subsequent perigee passage, it is injected into GTO by means of the velocity increment $\Delta \mathrm{V}_{2}$. In this study, the circularization $\Delta \mathrm{V}$ from GTO to GEO is considered to be provided by the kick motor of the payload. After payload delivery the two orbital platforms are reboosted by high-specific impulse electrical thrusters. The masses of the payloads to be handled by the tethered transfer system are assumed in the range $907 \mathrm{~kg}$ $4082 \mathrm{~kg}(2000 \mathrm{lb}-9000 \mathrm{lb})$ which according to present projections ${ }^{2}$ will constitute almost $80 \%$ of the traffic to GEO in the future.

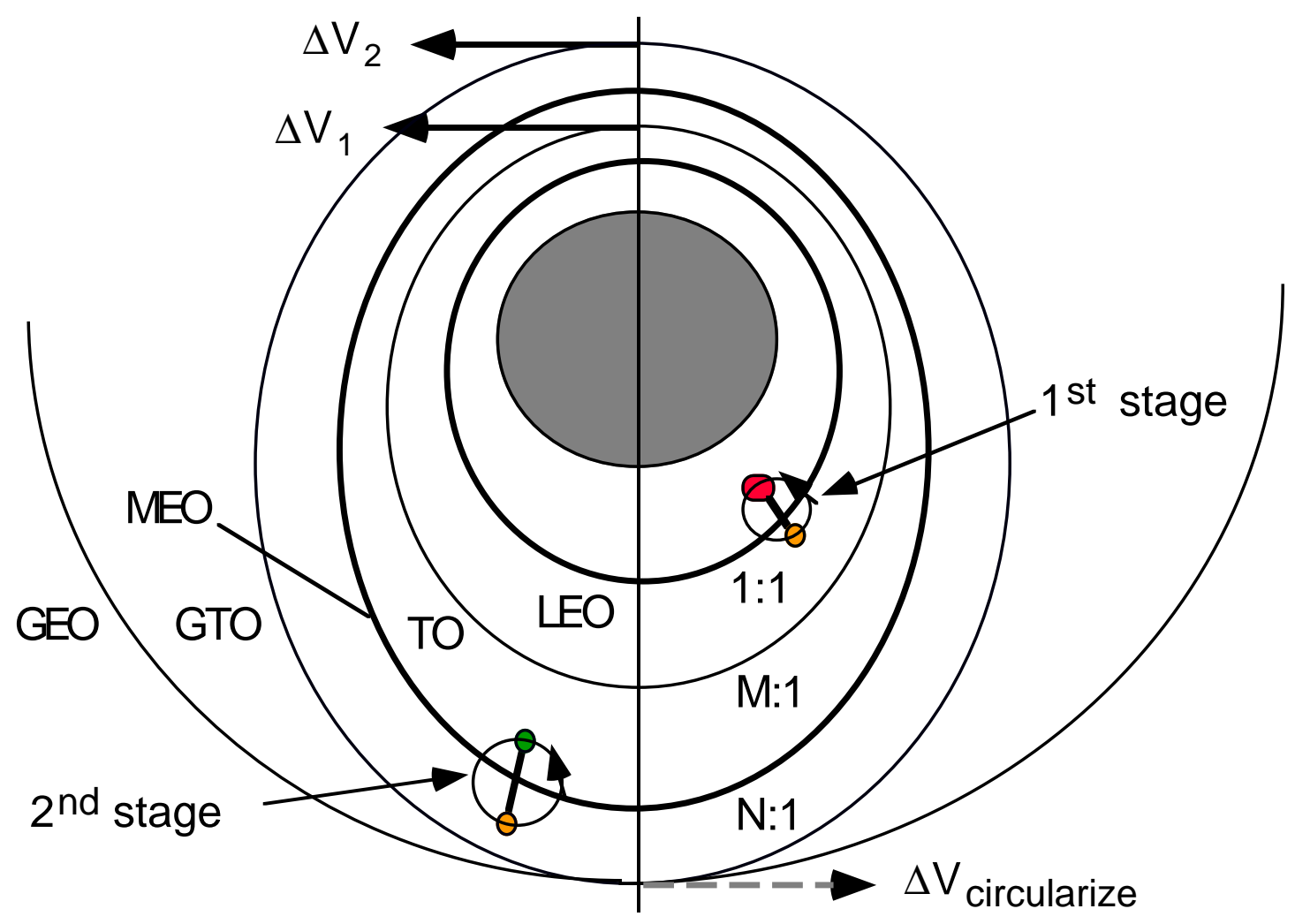

Fig. 1. Orbital sketch of two-stage tethered system for transferring satellites from low Earth orbit to geostationary. 


\section{Orbital Transfer with Tethers}

If we refer the system dynamics to a local vertical - local horizontal (LV-LH) reference frame attached to the system $\mathrm{CM}$, then tethers can be classified according to their motion with respect to LV-LH as hanging, swinging or spinning in much the same way as a pendulum in a gravity field (a tethered system in orbit is in fact a gravitygradient pendulum). Clearly, for a given tether length, spinning tethers can impart the highest $\Delta \mathrm{V}$ to the payload. If we call $\Delta \mathrm{H}$ the radial separation between the two tip masses half an orbit after release and L the tether length, the following simple rules ${ }^{4}$ apply (see Fig. 2):

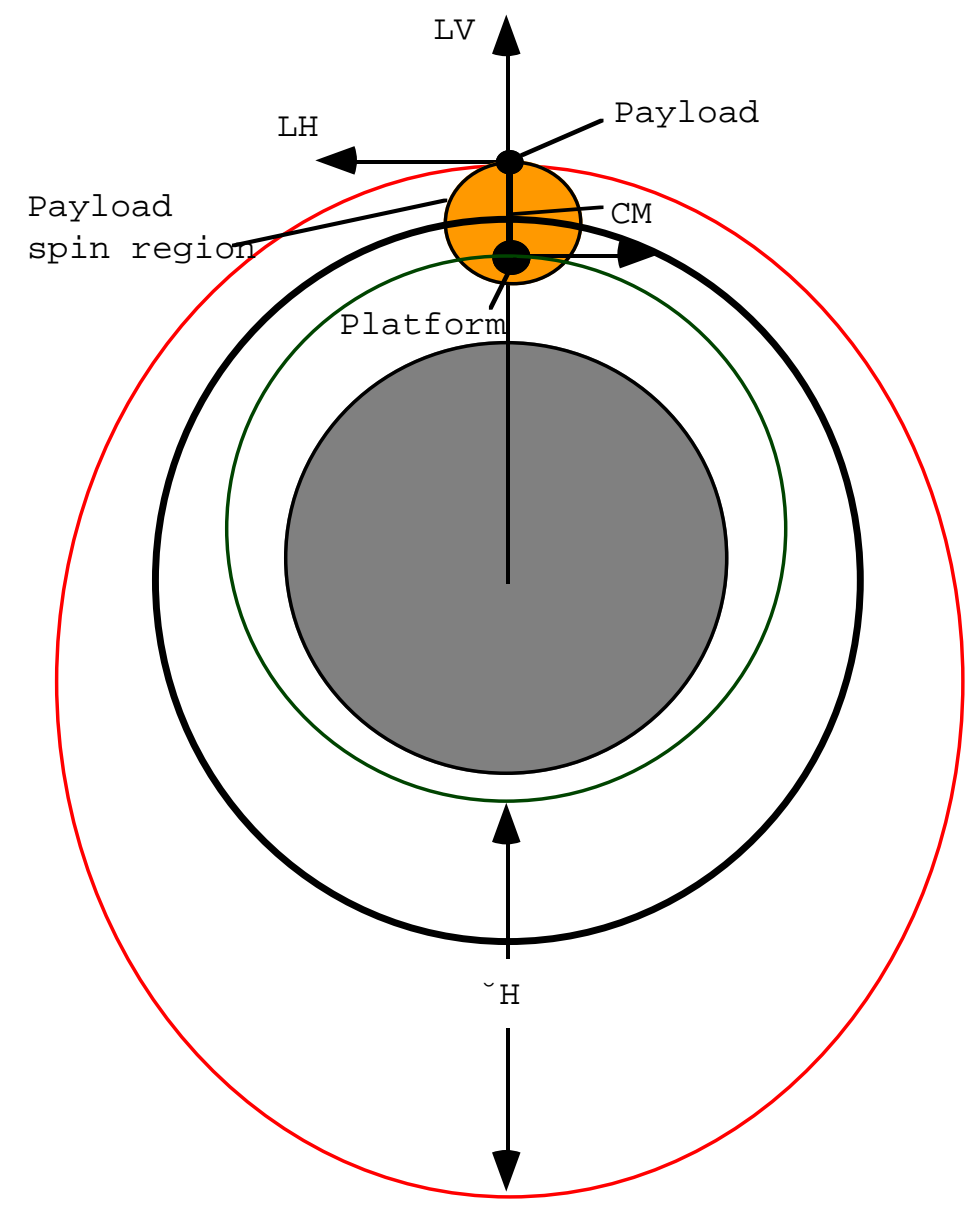

Fig. 2. Orbits after cut at local vertical (LV) of a spinning tether. 
$\Delta \mathrm{H} \approx 7 \mathrm{~L} \quad$ Hanging tethers

$7 \mathrm{~L}<\Delta \mathrm{H}<14 \mathrm{~L} \quad$ Swinging tethers

$\Delta \mathrm{H}>14 \mathrm{~L} \quad$ Spinning tethers

Given the fact that the required $\Delta \mathrm{Hs}$ (or alternatively $\Delta \mathrm{Vs}$ ) are very high for a transfer from LEO to GTO, spinning tethers are the only practical solution for achieving the desired goal with tethers of moderate lengths.

Tethers can have a constant cross section (cylindrical tethers) or a varying cross section (tapered tethers). The maximum velocity that a cylindrical spinning tether can sustain (the so called tether characteristic velocity), without any payload attached to its end, is limited by its material properties and can be written as:

$$
V_{c}=\sqrt{\frac{2 \sigma}{f \rho}}
$$

The $\Delta \mathrm{V}$ that a cylindrical tether can provide, therefore, is bounded. For example, the best tether material now available, Spectra 2000, has a $\mathrm{V}_{\mathrm{c}}=2.6 \mathrm{~km} / \mathrm{s}\left(\sigma=3.25 \times 10^{9}\right.$ $\mathrm{N} / \mathrm{m}^{2}$ and $\rho=970 \mathrm{~kg} / \mathrm{m}^{3}$ ) with a safety factor of 1 (no safety margin) and $\mathrm{V}_{\mathrm{c}}=1.96 \mathrm{~km} / \mathrm{s}$ with a safety factor of 1.75 as recommended for a fail-safe tether ${ }^{5}$.

Since the maximum stress is at the hub of a spinning tether, the tether can be tapered thus saving tether mass and removing the limitation on the maximum sustainable $\Delta \mathrm{V}$. The mass of an optimally (i.e., with a constant stress distribution) tapered tether can be written as a function of the tip mass (payload) $\mathrm{m}_{\text {pay }}$ as follows ${ }^{6,7}$ :

$$
\frac{m_{\text {tet }}}{m_{\text {pay }}}=\sqrt{\pi} \frac{V}{V_{c}} \exp \left(\frac{V^{2}}{V_{c}^{2}}\right) \operatorname{erf}\left(\frac{V}{V_{c}}\right)
$$

where $\mathrm{V}$ is the tip velocity and $\operatorname{erf}()$ is the error function. Figure 3 shows the tether/payload mass ratio for a cylindrical and a tapered tether of the same material (Spectra 2000) and a safety factor equal to 1.75. In conclusion, a tapered tether is lighter 
than a cylindrical tether for $\Delta \mathrm{V}>1 \mathrm{~km} / \mathrm{s}$ and moreover the $\Delta \mathrm{V}$ that a tapered tether can impart is not bounded by the strength to density ratio of the material. For $\Delta \mathrm{V}<1 \mathrm{~km} / \mathrm{s}$, the masses of Spectra-2000 cylindrical and tapered tethers are almost equal.

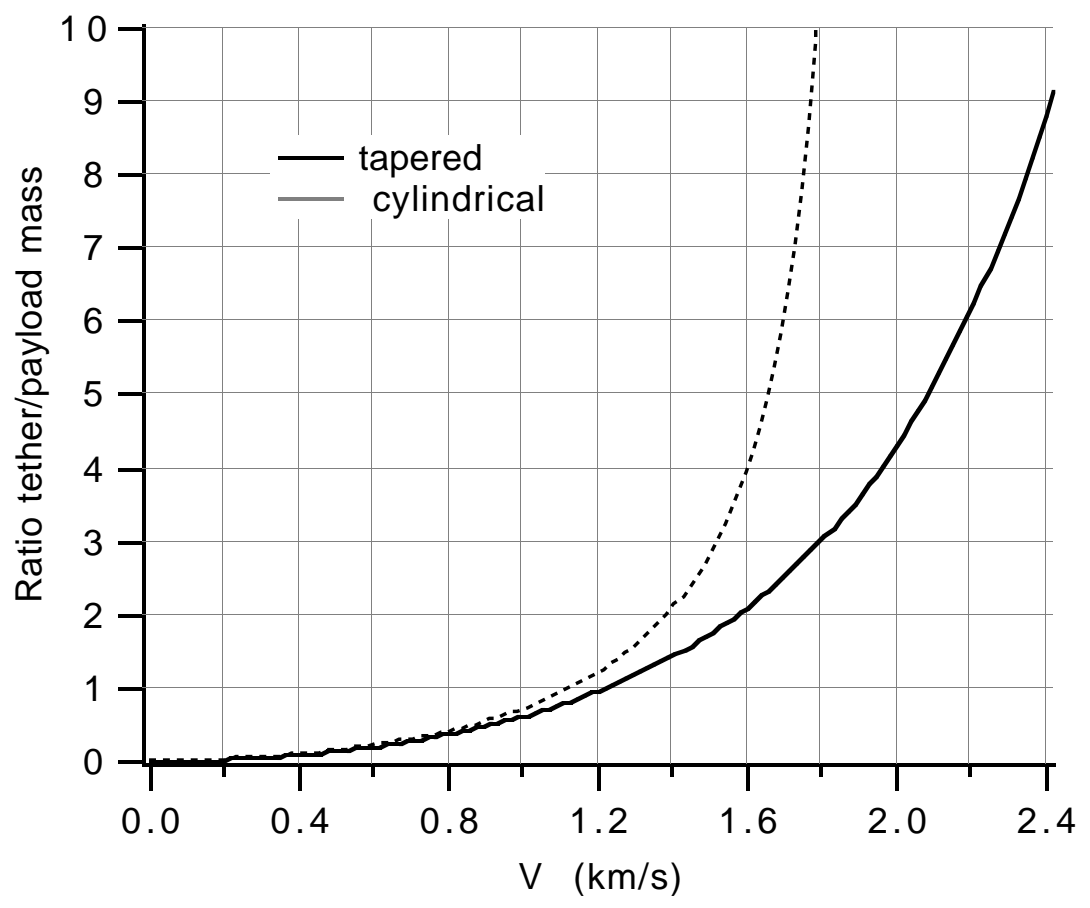

Fig. 3. Tether/payload mass ratio for cylindrical and tapered tethers of Spectra-2000 and safety factor $=1.75$.

\section{Staging}

In a zero-order approximation, a spinning tether can be compared to a rocket by comparing the tether mass needed to provide the desired $\Delta \mathrm{V}$ imparted to the payload and the propellant mass required to accomplish the same task. The ratio of the propellant mass $m_{\text {prop }}$ over the payload mass $m_{\text {pay }}$ is readily computed by the rocket equation

$$
\frac{m_{\text {prop }}}{m_{\text {pay }}}=\left[\exp \left(\frac{V}{I_{s p} g}\right)-1\right]
$$

$I_{\text {sp }} \mathrm{g}$, in Eq. (4), is simply the gas ejection velocity from the rocket nozzle which for a Hydrazine system and several solid propellants normally used in upper stages is about $3 \mathrm{~km} / \mathrm{s}$. 
Clearly, many other considerations apply to the comparison of tether systems vs. chemical propulsion (as shown later on in this paper) among which the most important one is that a tethered system is reusable while a chemical system is not. Nevertheless, Fig. 4 gives a good indication of the $\Delta \mathrm{V}$ range in which a spinning tether transportation system should operate with the best tether material presently available.

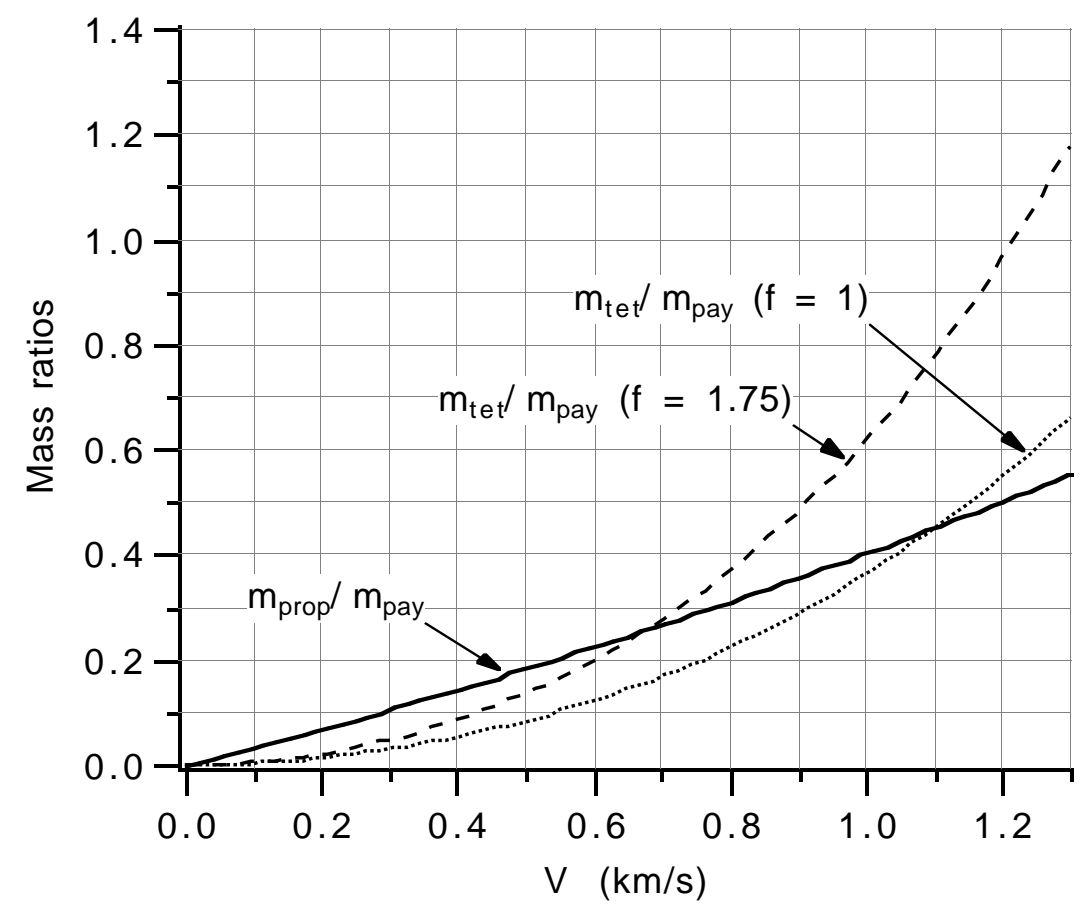

Fig. 4. Ratios of tether and propellant mass to payload mass vs. $\Delta \mathrm{V}$ for Spectra-2000 tethers ( $\mathrm{f}=$ load safety factor) and 300-s specific-impulse propellant.

Since a $\Delta V$ of $2.4 \mathrm{~km} / \mathrm{s}$ is required to inject a payload into GTO, if a single-stage tethered system (with present day tether materials) were to be used, the mass of the tether would be about 9 times the payload mass while the comparable propellant (Hydrazine) mass would be less than 2 times the payload mass. In other words, based on this highlysimplified analysis it would take about 5 launches for a single stage tethered system to become competitive. However, this preliminary conclusion can be improved dramatically by analyzing a two-stage system that by splitting the $\Delta \mathrm{V}$ into two smaller components utilizes the tethers at their best with present day tether materials. 


\section{Orbital Mechanics}

\section{$\underline{\text { Introductory Remarks }}$}

In a two-stage tethered system, the $1^{\text {st }}$ stage tether rotates with angular rate $\omega_{1}$ and orbits in a LEO orbit defined by its perigee $r_{1 p}$ and apogee radius $r_{1 a}$. The $2^{\text {nd }}$ stage, which rotates with an angular rate $\omega_{2}$, is at an intermediate orbit (MEO) between LEO and GEO. Both orbits lie on the equatorial plane. The orbit of the $2^{\text {nd }}$ stage is also elliptical in order to provide a velocity match at perigee, at the capture of the satellite released from the first stage, between the tether tip velocity and the incoming satellite that follows the transfer orbit (TO). For best efficiency, $\Delta \mathrm{Vs}$ are imparted at perigee where the energy produced by a given $\Delta \mathrm{V}$ is maximum because the orbital velocity is maximum.

An important consideration to keep in mind is the synchronicity ${ }^{5}$ between the LEO orbit, the transfer orbit (TO) after release from the $1^{\text {st }}$ stage and the MEO orbit of the $2^{\text {nd }}$ stage. Synchronicity between the orbits of the first and the second stage provides periodic encounters between the two stages once the lines of apses of the two orbits are close to being aligned. Synchronicity between the orbit of the second stage (MEO) and the transfer orbit of the payload (TO) provides multiple capture opportunities if the first capture attempt is missed.

\section{Orbital Perturbations}

The orbital model utilized in the following computations is simplified as it adopts a spherical gravity field and neglects environmental perturbations. While the latter assumption is adequate considering the orbits involved (see also Ref. 1), the former assumption must be qualified because of the role played by the Earth's oblateness (i.e., the $\mathrm{J}_{2}$ gravity component). Specifically, since the stages lie on the equatorial plane, the differential precession of the $1^{\text {st }}$ and $2^{\text {nd }}$ stage lines of apses is different from zero. The realignment frequency of the lines of apses determines the maximum launching frequency at minimum energy, i.e., a transfer whereby a negligible amount of energy is spent to correct for mismatches of the apsidal lines. The apsidal realignment period of the twostage orbital configuration analyzed in this paper is 72 days and, consequently, the ideal maximum launching frequency is 5 launches per year. Additional comments on techniques for compensating possible mismatches between the orbit of the stages are dealt with in the section Rendezvous and Capture of this paper. 


\section{Orbital Model}

The orbital periods $\mathrm{P}$ of the TO orbit and MEO orbit can be expressed as follows:

$$
\begin{aligned}
& \mathrm{P}_{\mathrm{TO}}=\mathrm{MP}_{1} \\
& \mathrm{P}_{2}=\mathrm{NP}_{1}
\end{aligned}
$$

The orbital period ratios $\mathrm{M}$ and $\mathrm{N}$ do not have to be necessarily integer numbers for having periodic encounters but rather rational numbers, i.e., $\mathrm{M}$ and $\mathrm{N}$ must satisfy the following equation in order to provide periodic encounters:

$$
\frac{M}{N}=\frac{K}{J} \quad \text { with } \mathrm{K} \text { and } \mathrm{J} \text { integer numbers }
$$

The satellite is first released by the $1^{\text {st }}$ stage at perigee, which in an ideal situation should have the same orbital anomaly of the perigee of the $2^{\text {nd }}$ stage. If the satellite is released when the tether crosses the local vertical, the perigee of TO is also at the point of release. After a time $\mathrm{T}_{\text {rev }}=\mathrm{NKP}_{1}$ (revisit time) the satellite passes through the perigee of TO when the $2^{\text {nd }}$ stage is close to the perigee of MEO (i.e., there are multiple recapture opportunities).

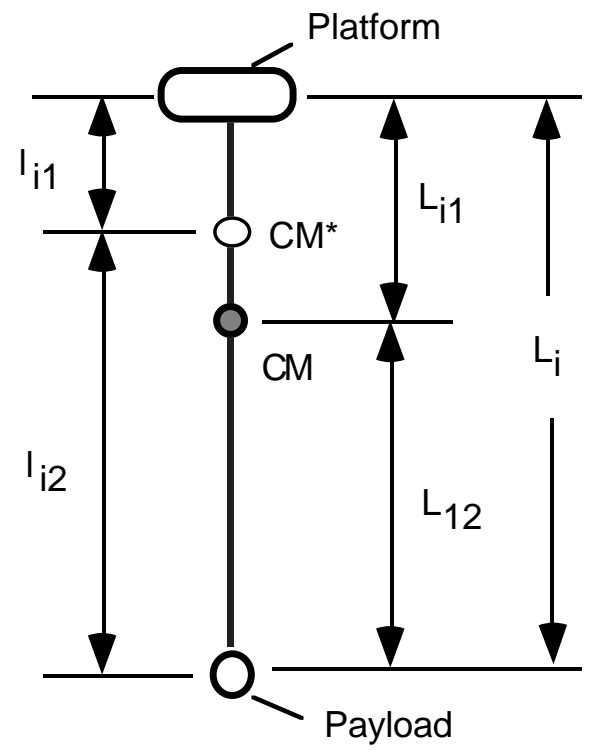

Fig. 5. Geometry of tethered stage. 
In Fig. 5, $\mathrm{L}_{1}=\mathrm{L}_{11}+\mathrm{L}_{12}=1_{11}+1_{12}$ and $\mathrm{L}_{2}=\mathrm{L}_{21}+\mathrm{L}_{22}=\mathrm{l}_{21}+\mathrm{l}_{22}$ are the overall lengths of the $1^{\text {st }}$ and $2^{\text {nd }}$ stage tethers. The variables denoted by capital $\mathrm{L}$ are the distances from the platform and the payload to the stage center of mass (CM) with the payload attached while the variables denoted by small 1 are the distances to the $\mathrm{CM}^{*}$ without the payload attached.

After defining $\chi_{i}=m_{\text {pay }} / \mathrm{m}_{\text {plat- } \mathrm{i}}$ and $\tau_{\mathrm{i}}=\mathrm{m}_{\text {tet-i } \mathrm{i}} / \mathrm{m}_{\text {plat- } \mathrm{i}}$, where $\mathrm{i}=1$ and 2 for the first and second stage respectively, we obtain for the distances to $\mathrm{CM}$ :

$$
\mathrm{L}_{\mathrm{i} 1}=\frac{2 \chi_{\mathrm{i}}+\tau_{\mathrm{i}}}{2\left(1+\chi_{\mathrm{i}}+\tau_{\mathrm{i}}\right)} \quad \mathrm{L}_{\mathrm{i}} ; \quad \mathrm{L}_{\mathrm{i} 2}=\frac{2+\tau_{1}}{2\left(1+\chi_{\mathrm{i}}+\tau_{\mathrm{i}}\right)} \quad \mathrm{L}_{\mathrm{i}} \quad \mathrm{i}=1,2
$$

and for the distances to $\mathrm{CM}^{*}$

$$
1_{\mathrm{i} 1}=\frac{\tau_{\mathrm{i}}}{2\left(1+\tau_{\mathrm{i}}\right)} \quad \mathrm{L}_{\mathrm{i}} ; \quad \mathrm{1}_{\mathrm{i} 2}=\frac{2+\tau_{\mathrm{i}}}{2\left(1+\tau_{\mathrm{i}}\right)} \quad \mathrm{L}_{\mathrm{i}} \quad \mathrm{i}=1,2
$$

The orbital velocity of the $1^{\text {st }}$ stage $\mathrm{CM}$ at perigee is:

$$
\mathrm{V}_{\mathrm{p} 1}=\sqrt{\frac{\mu}{\mathrm{r}_{\mathrm{p} 1}}} \sqrt{1+\mathrm{e}_{1}}
$$

where $r_{p 1}$ is the perigee radius and $e_{1}$ is the orbital eccentricity. The velocities at perigee of the second stage $\mathrm{CM}^{*}$ (before satellite capture) and of the satellite on its transfer orbit TO after release from the first stage are, respectively:

$$
\begin{aligned}
& \mathrm{V}_{\mathrm{p} 2}=\sqrt{\frac{\mu}{r_{p 1}}} \sqrt{\frac{2}{\left(L_{12}+l_{22}\right) / r_{p 1}+1}-\left(1-e_{1}\right) N^{(-2 / 3)}} \\
& \mathrm{V}_{\mathrm{pTO}}=\sqrt{\frac{\mu}{\mathrm{r}_{\mathrm{p} 1}}} \sqrt{\frac{2}{\mathrm{~L}_{12} / \mathrm{r}_{\mathrm{p} 1}+1}-\left(1-\mathrm{e}_{1}\right) \mathrm{M}^{(-2 / 3)}}
\end{aligned}
$$

Since $\omega_{1}=\frac{1}{L_{12}}\left(V_{p_{T O}}-V_{p 1}\right)$ and $\omega_{2}=\frac{1}{l_{22}}\left(V_{p 2}-V_{p_{T O}}\right)$, the rotational rates of the two stages are as follows: 


$$
\begin{aligned}
& \omega_{1}=\frac{1}{\mathrm{~L}_{12}} \sqrt{\frac{\mu}{\mathrm{r}_{\mathrm{p} 1}}}\left(\sqrt{\frac{2}{\mathrm{~L}_{12} / \mathrm{r}_{\mathrm{p} 1}+1}-\left(1-\mathrm{e}_{1}\right) \mathrm{M}^{(-2 / 3)}}-\sqrt{1+\mathrm{e}_{1}}\right) \\
& \omega_{2}=\frac{1}{\mathrm{l}_{22}} \sqrt{\frac{\mu}{\mathrm{r}_{\mathrm{p} 1}}} \\
& \left(\sqrt{\frac{2}{\left(\mathrm{~L}_{12}+\mathrm{l}_{22}\right) / \mathrm{r}_{\mathrm{p} 1}+1}-\left(1-\mathrm{e}_{1}\right) \mathrm{N}^{(-2 / 3)}}-\sqrt{\frac{2}{\mathrm{~L}_{12} / \mathrm{r}_{\mathrm{p} 1}+1}-\left(1-\mathrm{e}_{1}\right) \mathrm{M}^{(-2 / 3)}}\right)
\end{aligned}
$$

The velocity increment $\Delta \mathrm{V}_{1}$ imparted by the first stage and the perigee velocity of the satellite in the TO orbit are:

$$
\begin{aligned}
& \Delta \mathrm{V}_{1}=\omega_{1} \mathrm{~L}_{12} \\
& \mathrm{~V}_{\mathrm{pTO}}=\mathrm{V}_{\mathrm{p} 1}+\Delta \mathrm{V}_{1}
\end{aligned}
$$

The perigee radius of the satellite in $\mathrm{TO}$ is

$$
\mathrm{r}_{\mathrm{pTO}}=\mathrm{r}_{\mathrm{p} 1}+\mathrm{L}_{12}
$$

The second stage captures the incoming satellite at a velocity equal to $V_{p 2}-\omega_{2} L_{22}$ and accelerates it to a velocity $\mathrm{V}_{\mathrm{p} 2}+\omega_{2} \mathrm{~L}_{22}$, thereby producing a velocity increment $\Delta \mathrm{V}_{2}=2 \omega_{2} \mathrm{~L}_{22}=2 \mathrm{~V}_{\text {tip-2 }}$ while equation (11.a) yields $\Delta \mathrm{V}_{1}=\mathrm{V}_{\text {tip-1 }}$ for the first stage.

The $\Delta \mathrm{V}$ imparted by the second stage and the perigee velocity of the satellite in GTO after release are:

$$
\begin{aligned}
& \Delta \mathrm{V}_{2}=2 \omega_{2} \mathrm{~L}_{22} \\
& \mathrm{~V}_{\mathrm{pGTO}}=\mathrm{V}_{\mathrm{pTO}}+\Delta \mathrm{V}_{2}
\end{aligned}
$$

and the GTO perigee radius is

$$
\mathrm{r}_{\mathrm{pGTO}}=\mathrm{r}_{\mathrm{p} 1}+\mathrm{L}_{12}+2 \mathrm{~L}_{22}
$$


At the apogee of the geotransfer orbit, the orbit must be circularized with an additional velocity increment $\Delta \mathrm{V}_{\text {circ }}$ as follows:

$$
\Delta \mathrm{V}_{\text {circ }}=\sqrt{\frac{\mu}{\mathrm{r}_{\mathrm{aGTO}}}}-\mathrm{V}_{\mathrm{aGTO}}
$$

where $\mathrm{r}_{\mathrm{aGTO}}$ and $\mathrm{V}_{\mathrm{aGTO}}$ can be readily obtained from conservation of energy and angular momentum as shown later on. The circularization velocity increment is assumed to be provided by the apogee kick motor of the satellite.

\section{Minimization of System Mass}

The orbital design (defined among others by the parameters $\mathrm{M}, \mathrm{N}$ and $\mathrm{e}_{1}$ ) and the mass distribution of the system (defined by the parameters $\chi_{1}, \chi_{2}, \tau_{1}, \tau_{2}$ ) are derived in this section with the goal of minimizing the overall mass of the system.

Orbital constraint equations and tether-strength constraint equations are used to compute the parameters above. For a successful delivery of the payload into GTO, the apogee radius of the satellite orbit after release from the second stage must be equal to the geostationary radius. From conservation of energy and angular momentum we can readily obtain the apogee radius and velocity of the satellite after release as follows:

$$
\begin{aligned}
& \mathrm{r}_{\mathrm{aGTO}}=\frac{\mathrm{r}_{\mathrm{pGTO}}}{\frac{2 \mu}{\mathrm{r}_{\mathrm{pGTO}} \mathrm{V}^{2}{ }_{\mathrm{pGTO}}}-1} \\
& \mathrm{~V}_{\mathrm{aGTO}}=\mathrm{V}_{\text {pGTO }} \frac{\mathrm{r}_{\mathrm{pGTO}}}{\mathrm{r}_{\mathrm{aGTO}}}
\end{aligned}
$$

Algebraic manipulation of Eq. (14.a) leads to the following orbital-constraint equation:

$$
\begin{aligned}
& 2\left(\sqrt{2-\left(1-e_{1}\right) M^{-2 / 3}}+2 \frac{1+\tau_{2}}{1+\chi_{2}+\tau_{2}}\left(\sqrt{2-\left(1-e_{1}\right) N^{-2 / 3}}-\sqrt{2-\left(1-e_{1}\right) M^{-2 / 3}}\right)\right)^{-2} \\
& -\frac{r_{p 1}}{r_{a G T O}}-1 \approx 0
\end{aligned}
$$


which is valid, with good approximation, for $\mathrm{L}_{12}, \mathrm{l}_{22} \ll<\mathrm{r}_{\mathrm{p} 1}$.

The tether-strength constraint equation is obtained by simply imposing that the tether at $\mathrm{CM}$ withstands the mechanical load generated by the satellite and the tether spinning with tip velocity $\mathrm{V}_{\text {tip-2}}$. The tip velocities and not the $\Delta \mathrm{Vs}$ determine the structural strength of the stages. Consequently, the first stage tether must be designed to withstand a tip velocity $\mathrm{V}_{\text {tip-1 }}=\Delta \mathrm{V}_{1}$ and the second stage a tip velocity $\mathrm{V}_{\text {tip- } 2}=1 / 2 \Delta \mathrm{V}_{2}$. The second stage, therefore, utilizes the tether more efficiently than the first stage.

After adopting cylindrical tethers, which are perfectly adequate for a two-stage tethered system, the centrifugal force at the $\mathrm{CM}$ of the i-th stage is as follows:

$$
\mathrm{F}_{\mathrm{CM}}=\mathrm{L}_{\mathrm{i} 2} \omega_{\mathrm{i}}^{2} \mathrm{~m}_{\text {pay }}+\int_{0}^{L_{i 2}} \rho A \omega_{i}^{2} l d l=\frac{V_{t i p-i}^{2}}{L_{i 2}}\left(m_{\text {pay }}+\frac{1}{2} \rho A L_{i 2}\right) \quad \mathrm{i}=1,2
$$

At the design strength of the tether $\sigma \mathrm{A}=\mathrm{F}_{\mathrm{CM}}$ and, after recalling the definition of the tether characteristic velocity, Eq. (16) yields:

$$
\mathrm{V}_{\mathrm{c}}=\mathrm{V}_{\text {tip-i }} \sqrt{\frac{2}{L_{i 2}} \frac{m_{\text {pay }}}{\rho A}+1} \quad \mathrm{i}=1,2
$$

After several algebraic manipulations, Eq. (17) yields the tether-strength equation for the second stage as follows:

$$
\begin{aligned}
& \left(\sqrt{\frac{\mu}{\mathrm{r}_{\mathrm{p} 1}}} \frac{1+\tau_{2}}{1+\chi_{2}+\tau_{2}}\left(\sqrt{2-\left(1-\mathrm{e}_{1}\right) \mathrm{N}^{-2 / 3}}-\sqrt{2-\left(1-\mathrm{e}_{1}\right) \mathrm{M}^{-2 / 3}}\right)\right) \\
& \sqrt{\frac{4\left(1+\chi_{2}+\tau_{2}\right)}{2+\tau_{2}} \frac{\chi_{2}}{\tau_{2}}+1}-\mathrm{V}_{\mathrm{c}} \approx 0
\end{aligned}
$$

The orbital constraint for the first stage is imposed on the perigee radius of the platform after release. In order to prevent the platform from reentering after release of the payload, we impose a minimum perigee altitude after release $r_{\min }$. By utilizing again the conservation of angular momentum, as expressed in Eq. (14.a), we obtain the following orbital constraint equation for the first stage: 


$$
2\left(\sqrt{1+\mathrm{e}_{1}}-\frac{2 \chi_{1}+\tau_{1}}{2+\tau_{1}}\left(\sqrt{2-\left(1-\mathrm{e}_{1}\right) \mathrm{M}^{-2 / 3}}-\sqrt{1+\mathrm{e}_{1}}\right)\right)^{-2}-\frac{\mathrm{r}_{\mathrm{p} 1}}{\mathrm{r}_{\min }}-1 \approx 0
$$

and the tether-strength constraint as follows:

$$
\sqrt{\frac{\mu}{\mathrm{r}_{\mathrm{p} 1}}}\left(\sqrt{2-\left(1-\mathrm{e}_{1}\right) \mathrm{M}^{-2 / 3}}-\sqrt{1+\mathrm{e}_{1}}\right) \sqrt{\frac{4\left(1+\chi_{1}+\tau_{1}\right)}{2+\tau_{1}} \frac{\chi_{1}}{\tau_{1}}+1}-\mathrm{V}_{\mathrm{c}} \approx 0
$$

Equations (15), (18), (19), (20) must be solved for different values of the orbital ratios $\mathrm{M} / \mathrm{N}$ as specified by Eq. (6).

The value of orbital eccentricity $\mathrm{e}_{1}$ of the first stage is defined by the requirement that the first stage be reachable by ground launchers. The perigee radius and the eccentricity determine the energy of the first stage orbit as $E=-\mu /\left(2 a_{1}\right)$ where $a_{1}=r_{p 1} /\left(1-e_{1}\right)$. Clearly the greater $\mathrm{e}_{1}$ the smaller the total $\Delta \mathrm{V}$ that the upper stage must provide to achieve GTO but also the greater the energy required to the ground launcher. Also, the smaller the perigee radius $r_{p 1}$ the smaller the energy. However, $r_{p 1}$ must be such that the altitude of the first stage is well above the dense atmosphere. We have adopted a perigee altitude of $450 \mathrm{~km}$ (i.e., $\mathrm{r}_{\mathrm{p} 1}=6828 \mathrm{~km}$ ) and an orbital eccentricity $\mathrm{e}_{1}=0.1$ which defines an orbit of the first stage that is reachable by a number of existing launchers and likely by the presently-under-development RLV (Reusable Launch Vehicle).

Equations (15), (18), (19) and (20) have been solved numerically for $\chi_{1}, \chi_{2}, \tau_{1}, \tau_{2}$ for various orbital period ratios in order to determine the total mass of the system. Figure 6 shows the ratio of the total system mass (without payload) over the payload mass for ratios $\mathrm{M} / \mathrm{N}=1 / 2,1 / 3$ and $1 / 4$ and $\mathrm{M}$ ranging from 1 to 2.2. It is worth reminding that $\mathrm{M}$ is the ratio between the TO and $\mathrm{LEO}$ orbital periods while $\mathrm{N}$ is the ratio between the MEO and LEO orbital periods. The equations above also show that the mass ratios of the first stage are not coupled to the mass ratios of the second stage while the equations for the two stages are coupled through the orbital period ratios $\mathrm{M}$ and $\mathrm{N}$.

Low total masses are obtained for $\mathrm{M} / \mathrm{N}=1 / 3$ and $\mathrm{M} / \mathrm{N}=1 / 4$. A ratio of $1 / 3$ has two significant advantages over a ratio of $1 / 4$ as follows: (a) the revisit time (proportional to $\mathrm{N}$ ) is shorter and (b) the platform-2/tether-2 mass ratio ( $2^{\text {nd }}$ stage) is more favorable as it allows for a bigger platform that can better accommodate subsystems and propellant. 


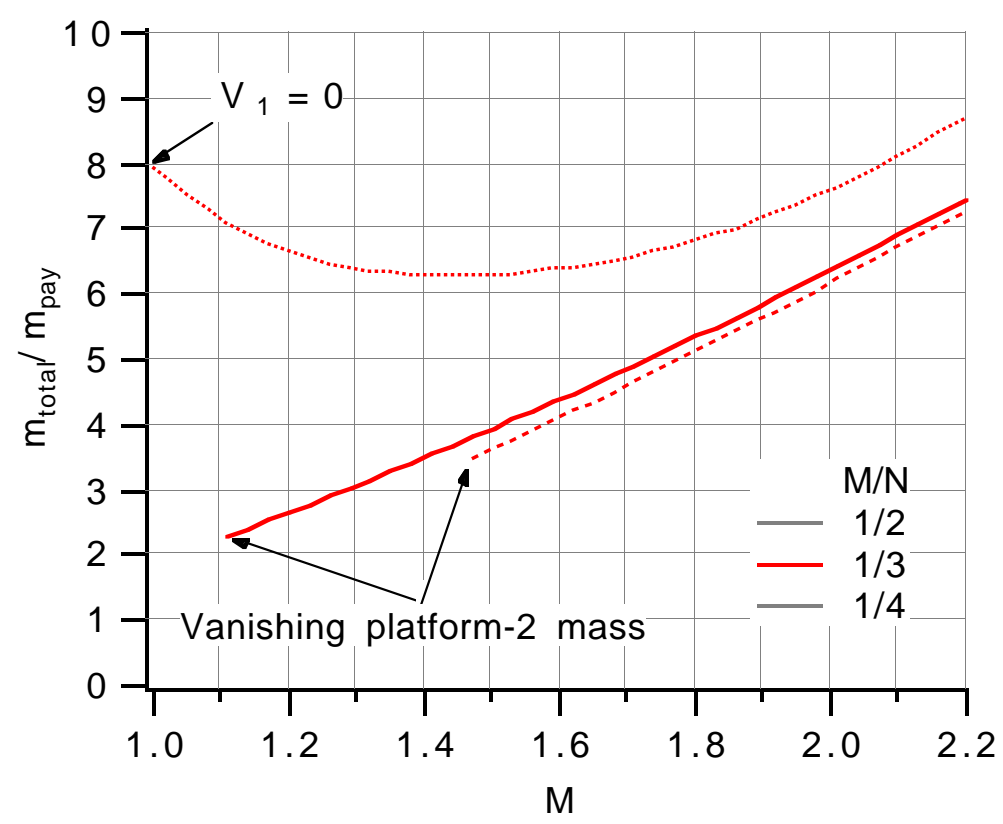

Fig. 6. Total/payload mass ratio for various orbital period ratios $\mathrm{M} / \mathrm{N}$.

Small values of $\mathrm{M}$ would appear appealing at first glance from Fig. 6 but such small values lead to a vanishing mass of the $2^{\text {nd }}$-stage platform. Since several heavy subsystems (e.g., power) must be placed in the platform, we adopt (see Fig. 7) the value $\mathrm{M}=1.5$ that provides the highest value of the platform/payload mass ratio for the $2^{\text {nd }}$ stage. Consequently, our selection is $\mathrm{M}=1.5$ and $\mathrm{N}=4.5$ which also leads to a sensible mass value (see Fig. 8) of the first stage service module (platform-1).

The total mass of the system (without reboost propellant and payload) is, in conclusion, only 4 times the payload mass. This result is rather appealing when considering the mass of existing upper stages (more on this point later) and previous studies of spinning systems designed to provide a $\Delta \mathrm{V}$ of $1.2 \mathrm{~km} / \mathrm{s}$ (i.e., half the $\Delta \mathrm{V}$ provided by the system under investigation) which resulted in system masses 30 times the payload mass ${ }^{8}$.

An analysis of the relevant equations also leads to the conclusion that the tether lengths play a negligible role in defining the system mass. The tether lengths, however, define the spin rates of the two stages (see Eqs. 10.a and 10.b) and, consequently, determine the acceleration at rendezvous and the acceleration acting on the payload attached to the spinning stages. 


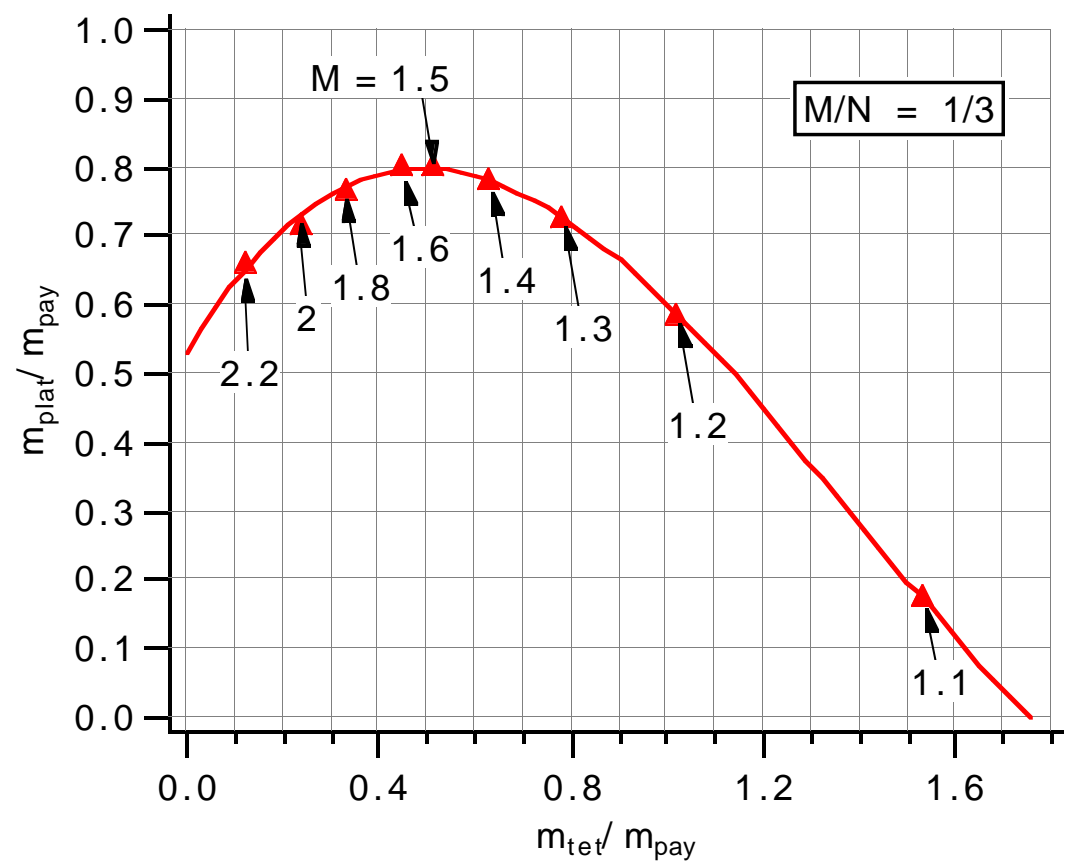

Fig. 7. Platform/payload mass ratio vs. tether/payload mass ratio for $2^{\text {nd }}$ stage.

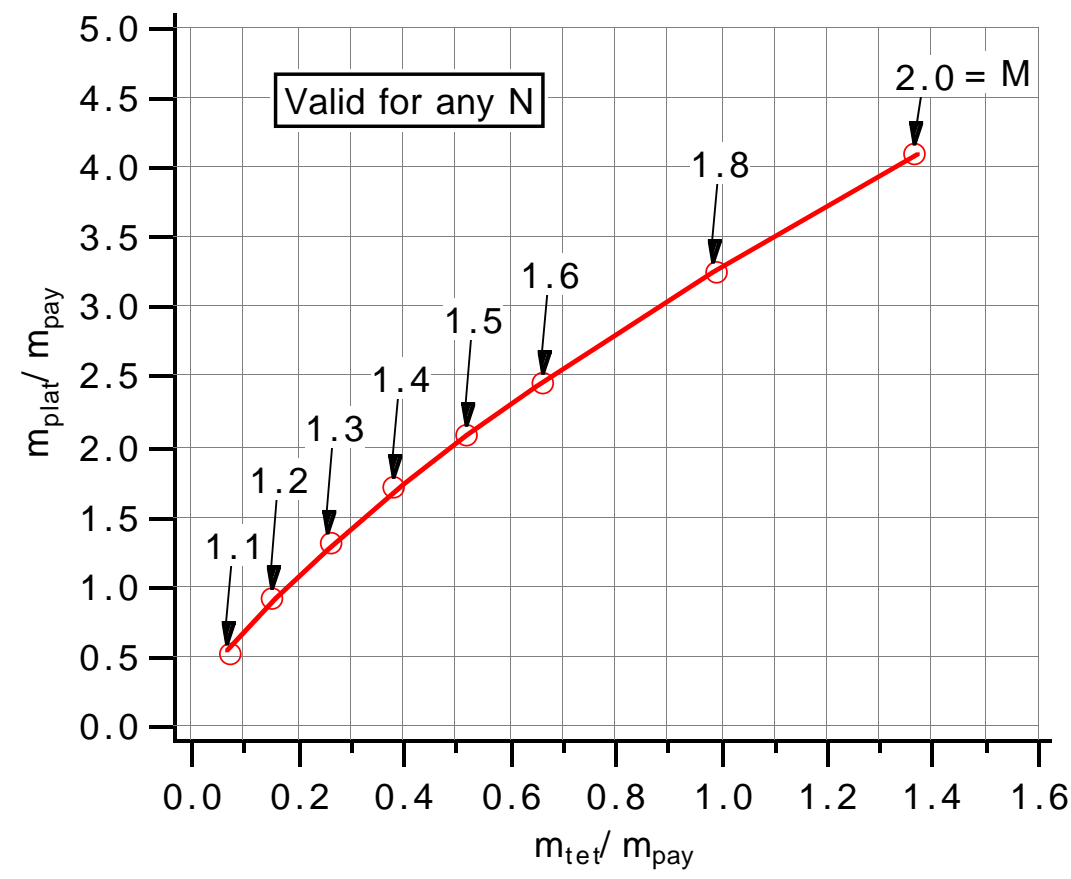

Fig. 8. Platform/payload mass ratio vs. tether/payload mass ratio for $1^{\text {st }}$ stage. 


\section{Numerical Cases}

By using the equations and parameters derived in the previous section, the orbits and other key system data have been computed and the results are shown in Table 1. This analysis neglects the effect of air drag (which was proven to be very small in Ref. 1) and higher-order gravity effects. However, the effect of the $\mathrm{J}_{2}$ gravity term on the differential precession of the apsidal lines of the two stages can not be forgotten. This effect, as a matter of fact, determines the payload transfer frequency of the two-stage system. The ideal maximum transfer frequency is equal to the realignment frequency of the apsidal lines of the stages. For the orbital design derived in this paper, the frequency of apsidal realignment (and consequently the transfer frequency) is equal to once every 72 days and, consequently, the maximum launch rate is 5 launches per year.

The results presented in this section were derived for the heaviest payloads predicted in the traffic model, that is, telecommunication satellites of $4082 \mathrm{~kg}$ (9000-lb class) which are heavier than an Intelsat VII. Table 1 also shows comparable results for a singlestage, 90-km-long system that uses a tapered Spectra-2000 tether to inject the payload directly into the GTO orbit. Clearly, the launch frequency of the single stage is not determined by the realignment of apsidal lines but rather by the time required for rebuilding the total (i.e., orbital and rotational) angular momentum lost by the stage after each transfer. A few weeks are required with present-technology ion thrusters for an efficient reboosting of the stage

\section{Power, Reboost Propellant and System Mass}

Ion thrusters with a specific impulse of $1500 \mathrm{~s}$ were assumed for reboosting the stages after each launch. As shown in Table 2 (see Ref. 1), 5 missions per year with the heaviest payloads and a 2-year interval between propellant deliveries were also assumed to compute the power and propellant consumption. Power demand can be lowered and propellant increased by lowering the specific impulse of the thrusters. The low propellant mass required to cover 10 launches over a 2-year cycle highlights one of the fundamental characteristic of this transportation system, that is, the system combines the efficiency of electrical propulsion with the delivery speed of a chemical upper stage.

The total mass of the system for 10 launches over 2 years of operation is $21400 \mathrm{~kg}$ that is divided between $16020 \mathrm{~kg}$ of empty system mass (at end of life) and $5380 \mathrm{~kg}$ of reboost propellant (see Table 3). A chemical upper stage with comparable payload capacity to GTO (e.g., IUS) has a total mass of $14800 \mathrm{~kg}$ inclusive of propellant for 
Table 1. Key parameters of (a) two-stage tethered system from LEO to GEO for orbital ratios $\mathrm{M}=1.5, \mathrm{~N}=4.5$ and (b) single-stage tethered system.

\begin{tabular}{|c|c|c|}
\hline $\begin{array}{c}\underline{\text { Items }} \\
\text { Distances }(\mathrm{km}), \text { Masses }(\mathrm{kg})\end{array}$ & Two-stage & $\begin{array}{l}\text { Single-stage } \\
\text { (tapered tether) }\end{array}$ \\
\hline $1^{\text {st }}$ stage mass ratio & $\chi_{1}=0.479, \tau_{1}=0.248$ & $\chi_{1}=0.5, \tau_{1}=4.45$ \\
\hline $2^{\text {nd }}$ stage mass ratio & $\chi_{2}=1.245, \tau_{2}=0.643$ & N/A \\
\hline LEO eccentricity & $\mathrm{e}_{1}=0.1$ & $\mathrm{e}_{1}=0.1$ \\
\hline Capture revisit time (hr:min) & $8: 10$ & N/A \\
\hline LEO-GEO transfer time (hr:min) & $16: 50$ & $5: 18$ \\
\hline $1^{\text {st }}$ stage tether length & $\mathrm{L}_{1}=60 \mathrm{~km}$ & $\mathrm{~L}_{1}=90 \mathrm{~km}$ \\
\hline $2^{\text {nd }}$ stage tether length & $\mathrm{L}_{2}=80 \mathrm{~km}$ & N/A \\
\hline $1^{\text {st }}$ stage CM orbit (radii) & $6828 \times 8345$ & $6828 \times 8345$ \\
\hline (altitudes) & $450 \times 1967$ & $450 \times 1967$ \\
\hline $2^{\text {nd }}$ stage $\mathrm{CM}$ orbit & $6931 \times 34426$ & N/A \\
\hline Payload orbit after $1^{\text {st }}$ stage release & $6867 \times 13016$ & $6877 \times 42165$ \\
\hline Payload orbit after $2^{\text {nd }}$ stage release & $6940 \times 42165$ & N/A \\
\hline Inertial rotational rate $\omega_{1}(\mathrm{rad} / \mathrm{s})$ & 0.0180 & 0.040 \\
\hline Inertial rotational rate $\omega_{2}(\mathrm{rad} / \mathrm{s})$ & 0.0166 & N/A \\
\hline$\Delta \mathrm{V}_{1}=\mathrm{V}_{\mathrm{tip}-1}(\mathrm{~km} / \mathrm{s})$ & 0.70 & 1.97 \\
\hline$\Delta \mathrm{V}_{2}=2 \mathrm{~V}_{\text {tip- }}(\mathrm{km} / \mathrm{s})$ & 1.21 & N/A \\
\hline$\Delta \mathrm{V}_{1}+\Delta \mathrm{V}_{2}(\mathrm{~km} / \mathrm{s})$ & 1.91 & N/A \\
\hline$\Delta \mathrm{V}_{\text {circ }}(\mathrm{km} / \mathrm{s})$ (not supplied by tether) & 1.44 & 1.44 \\
\hline Payload acceleration on $1^{\text {st }}$ stage & 1.0 & 8.1 \\
\hline LV acceleration at capture (g) & 1.8 & N/A \\
\hline LH acceleration at capture (g) & 0 & N/A \\
\hline Tether-1 mass & 2110 & 36340 \\
\hline Platform-1 mass & 8520 & 8160 \\
\hline $1^{\text {st }}$ stage mass & 10630 & 44500 \\
\hline Tether- 2 mass & 2110 & N/A \\
\hline Platform-2 mass & 3280 & N/A \\
\hline $2^{\text {nd }}$ stage mass & 5390 & N/A \\
\hline Mass Grand Total (at end of life) & 16020 & 44500 \\
\hline
\end{tabular}


one launch. Consequently, the two-stage tethered system is more competitive than its chemical counterpart, on a mass basis, after two launches. Other considerations related to providing redundancies over the long operating time can increase the mass estimate of this tethered system if the system is required to be completely independent of ground servicing.

Table 2. Power and propellant mass of a two-stage LEO-to-GEO tether system for 10 transfers over 2 years.

\begin{tabular}{ccccc}
\hline \hline $\begin{array}{c}\text { Power }(\mathrm{kW}) \\
1^{\text {st }} \text { Stage }\end{array}$ & $\begin{array}{c}\text { Propellant }(\mathrm{kg}) \\
1^{\text {st }} \text { Stage }\end{array}$ & $\begin{array}{c}\text { Power }(\mathrm{kW}) \\
2^{\text {nd }} \text { Stage }\end{array}$ & $\begin{array}{c}\text { Propellant }(\mathrm{kg}) \\
2^{\text {nd }} \text { Stage }\end{array}$ & $\begin{array}{c}\text { Total } \\
\text { Propellant }(\mathrm{kg})\end{array}$ \\
\hline 13 & 1960 & 22 & 3420 & 5380 \\
\hline \hline
\end{tabular}

Table 3. Mass of a two-stage LEO-to-GEO tether system for 10 transfers over 2 years.

\begin{tabular}{ccccc}
\hline \hline $\begin{array}{c}\text { Dry Mass (kg) } \\
1^{\text {st }} \text { Stage }\end{array}$ & $\begin{array}{c}\text { Dry Mass (kg) } \\
2^{\text {nd }} \text { Stage }\end{array}$ & $\begin{array}{c}\text { Total Dry } \\
\text { Mass (kg) }\end{array}$ & $\begin{array}{c}\text { Total Propellant } \\
\text { Mass (kg) }\end{array}$ & $\begin{array}{c}\text { Total System } \\
\text { Mass (kg) }\end{array}$ \\
\hline 10630 & 5390 & 16020 & 5380 & 21400 \\
\hline \hline
\end{tabular}

\section{$\underline{\text { Lighter Payloads }}$}

The case shown in Tables 1 and 2 is for the heaviest payloads of $4082 \mathrm{~kg}$ (9000 lb). The system however can handle any lighter payload with ease. Lighter payloads in fact only require adjustments of the rotational rates of the two stages and a few kilometer adjustments of the orbits in order to compensate for the shift of the CMs of the two stages due to the lighter payloads.

\section{Tether Sizes}

Fail-safe tethers will likely be the preferable candidates for spinning tethers. If we assume, for the sake of picturing the size, that the tethers are cylindrical with solid cross 
section, the tether diameters for the two-stage system under consideration would be $6.8 \mathrm{~mm}$ for the $1^{\text {st }}$ stage tether and $5.9 \mathrm{~mm}$ for the $2^{\text {nd }}$ stage.

\section{Tether Rebound}

One important issue relevant to the release of heavy payloads with long tethers is the recoil of the tether after release and the transient dynamics of the system after payload capture. The issue of tether recoil was treated in Ref. 9 where the release dynamics of heavily-loaded tethers was analyzed. The solution adopted for eliminating the rebound was to generate, by reeling in and out tether at the deployer, a tension elastic wave along the tether before payload release. The payload is, then, released when the value of the tension, produced by the tension wave at the opposite tether tip where the tether grabbing/release mechanism is located, is equal to the steady state value of the tether tension after the payload has been released. The case analyzed in Ref. 9 was an $80-\mathrm{km}$ tether and the tension was reduced, without incurring any slackness, to $5 \%$ of its original value with a tension wave produced by reeling in and out about $500 \mathrm{~m}$ of tether length. Numerical simulations were utilized to prove the validity of the technique ${ }^{9}$. A similar strategy was utilized and simulated in Ref. 10 for reducing the transient dynamics after the capture of a payload by a spinning tether system capable of providing $1 \mathrm{~km} / \mathrm{s}$ velocity increment (i.e., comparable to the velocity increments under analysis in this paper).

\section{Transfer Time and Revisit Time}

The total transfer time from LEO to GEO in case the satellite is captured at the first attempt is 16:50 hr:min. The revisit time $\mathrm{T}_{\text {rev }}=\mathrm{NKP}_{1}$ between the $2^{\text {nd }}$ stage and the satellite released from the $1^{\text {st }}$ stage in case of miscapture is equal to 8:10 hr:min.

\section{Flow of Angular Momentum}

The tethered system discussed here is reversible: it can be used to transport spent satellites from GEO to LEO. In this case the $2^{\text {nd }}$ stage would capture the satellite at the top of its spin and release at the bottom of its spin to rendezvous with the $1^{\text {st }}$ stage. Another interesting feature is that thanks to conservation of angular momentum, if a satellite is transferred to GEO and an equal-mass satellite is retrieved from GEO at the next available opportunity, no propellant is required for reboosting the stages. Clearly, in a realistic situation the return traffic will be different from the outgoing traffic and some propellant will be necessary for making up the deficit of angular momentum and also for orbital phasing. The return traffic besides being important in itself can also 
provide sizable savings to the propellant budget of the system which is worth further analysis.

\section{Rendezvous and Capture}

One of the important aspect of a two-stage tethered system is the capture of the satellite by the second stage. A few important points must be stressed regarding this particular rendezvous and capture as follows: (a) the relative velocity at capture is zero; (b) the horizontal component of the relative acceleration is zero; (c) the vertical component of the relative acceleration is about $1.8 \mathrm{~g}$ for the case analyzed; and (d) the timing of the rendezvous maneuver is faster than a conventional rendezvous.

Simulations of the rendezvous and capture phase were carried out with a simplified model that simulates the dynamics in the equatorial plane and neglects air drag and higher-order gravity harmonics. The trajectory of the payload as seen from the tip of the $2^{\text {nd }}$ stage is shown in Fig. 9. The dotted line in the figure is the trajectory that the payload would follow if it is not captured by the $2^{\text {nd }}$ stage. The relative velocity and acceleration between the tip of the $2^{\text {nd }}$ stage and the incoming payload are shown in Figs. 10(a) and 10(b).

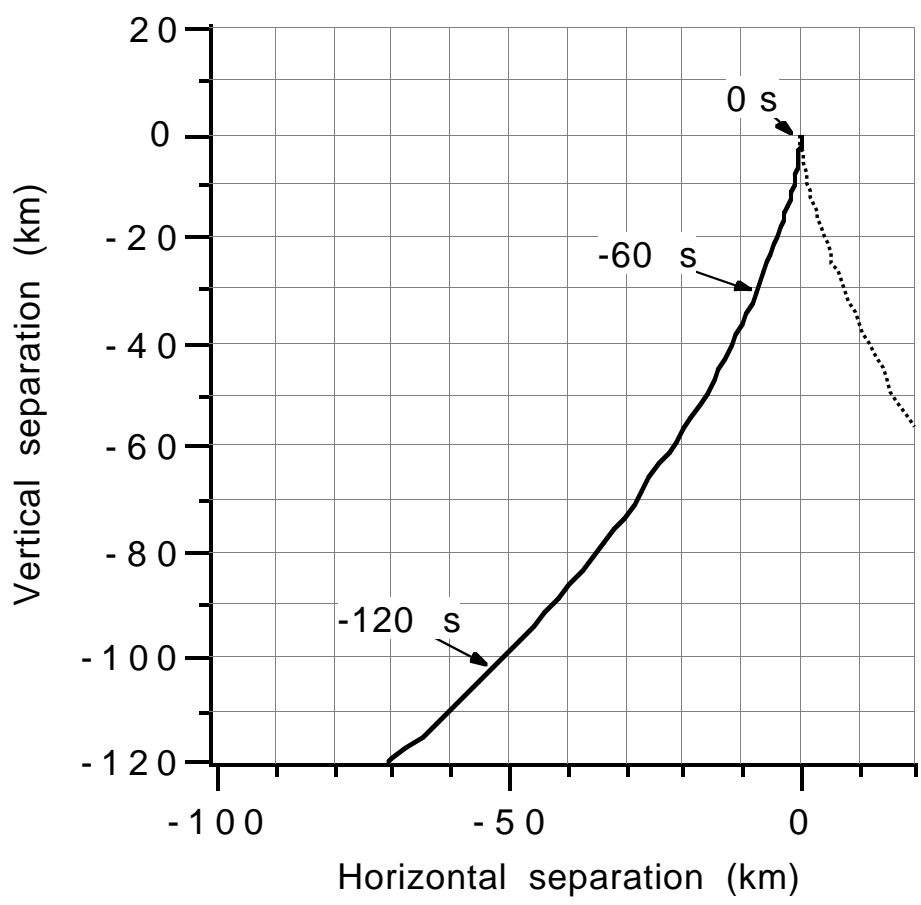

Fig. 9. Trajectory of rendezvous and capture of payload by $2^{\text {nd }}$ stage (payload escape trajectory shown in dashed line). 


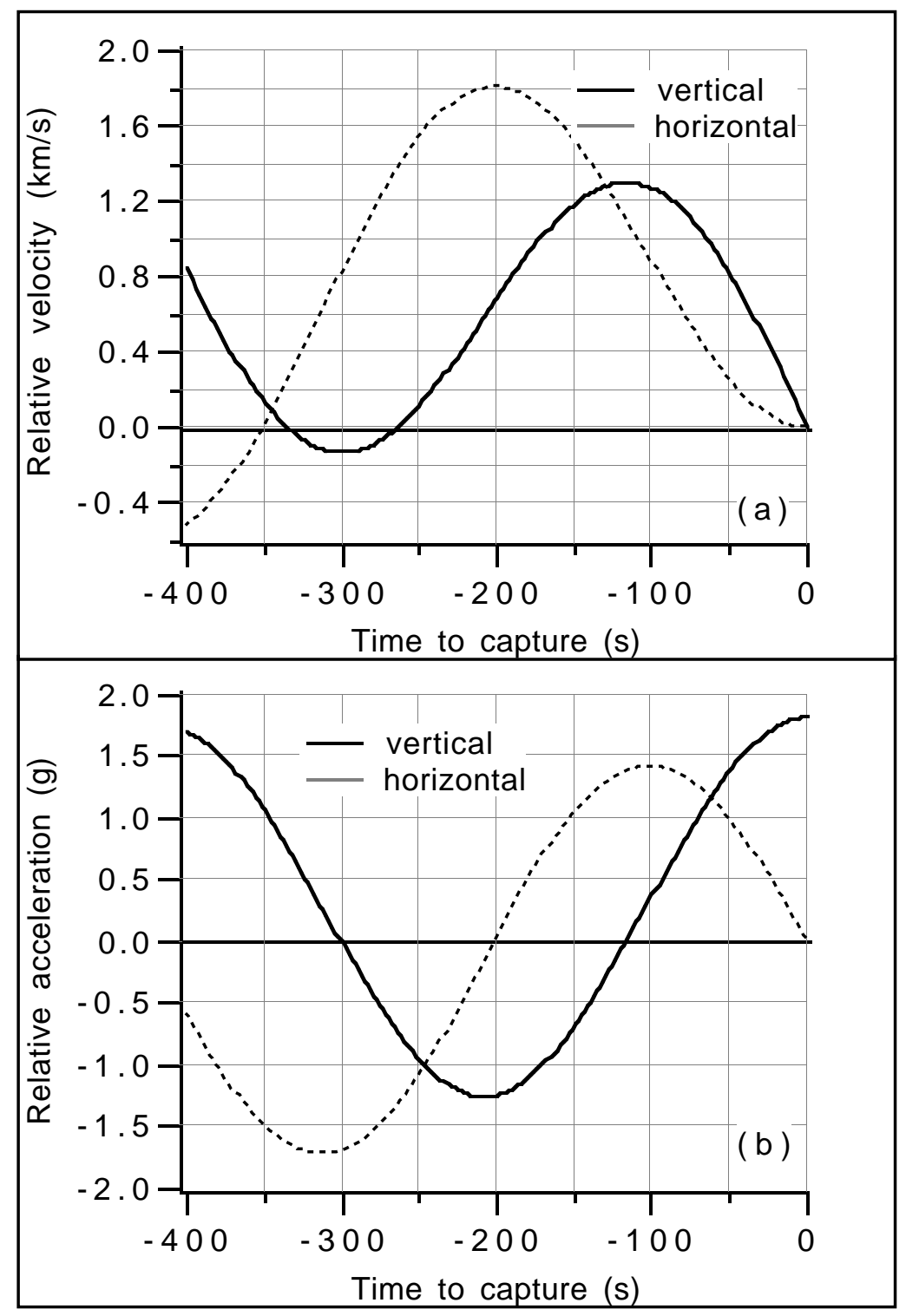

Figs. 10(a-b). Rendezvous and capture dynamics of payload by $2^{\text {nd }}$ stage: (a) relative velocity components and (b) relative acceleration components.

Considering that the vertical acceleration is the only non-zero component at capture, the capture maneuver is fairly similar (except for the g value) to capturing an object, thrown in the air from the ground, at the top of its parabolic trajectory with the hand moving at the same horizontal velocity of the object. The only non-zero component at capture is, in both cases, the vertical acceleration that is equal to $1 \mathrm{~g}$ on the ground and $1.8 \mathrm{~g}$ for the tethered system under consideration. The vertical component of the relative acceleration at capture is simply as follows $\mathrm{a}_{\max }=V_{\text {tip }}^{2} / l_{22}$. Consequently, the value of 
the maximum relative acceleration can be reduced by utilizing a longer tether for the second stage without requiring significant changes to the rest of the system.

Orbital mismatches at capture can be compensated for by adjusting the time of payload release and the spin rate of the first stage. For example, the line of apses of the payload transfer orbit (after release from the $1^{\text {st }}$ stage) can be rotated by changing the time of payload release during the spin. A payload release with the tether crossing the local vertical produces a $\Delta \mathrm{V}$ with no vertical component and therefore no rotation of the line of apses. On the contrary, a release off the local vertical advances or retards the position of the line of apses and, consequently, can correct possible mismatches along the orbital track. For example, releasing the payload $5^{\circ}$ before or after the local vertical rotates the lines of apses of the first stage orbit by $\pm 1.7^{\circ}$ (a $5^{\circ}$ phase shift at release corresponds to a time shift of $4.8 \mathrm{~s}$ for the payload release from the $1^{\text {st }}$ stage.) A $1.7^{\circ}$ rotation of the line of apses of the transfer orbit equals a 202-km along-track error of the position of the $2^{\text {nd }}$ stage at payload capture.

A radial error of the second stage at capture can be compensated for by adjusting the spin rate of the first stage. This adjustment can be done without any propellant consumption by simply changing the tether length, i.e., utilizing the conservation of angular momentum. A reduction or increase of the first stage tether length of $3.1 \%$ of the full length produces a change of the transfer orbit apogee altitude of $200 \mathrm{~km}$. Consequently, a radial error of $200-\mathrm{km}$ can be compensated with a $1.9-\mathrm{km}$ change of the $1^{\text {st }}$ stage $60-\mathrm{km}$ tether length.

A comprehensive analysis of the payload rendezvous and capture is beyond the scope of this paper. A conceptual design of the capture devise and a preliminary analysis of the sensors and actuators required for the rendezvous and capture was carried out in Ref. 1 . The conclusion from that study is that the sensors and actuators requirements are within the state of the art and that given the availability of differential GPS navigation there are no critical impediments to this type of rendezvous. However, further analyzes are needed for a more in-depth definition of the hardware involved.

\section{Recommendations for Further Analysis}

This paper focuses on some of the critical issues related to developing a spinning tether architecture for transferring payloads from LEO to GEO. A number of key issues 
have also been analyzed in other references ${ }^{1,9,10}$. There is, however, a number of topics that are recommended for further analysis as follows:

- Evaluating the influence of environmental perturbations over time and devising the necessary adjustments;

- Developing strategies for guidance and control during rendezvous and docking;

- Assessing the flow of angular momentum and the use of the return traffic to restore momentum;

- Incorporating the techniques developed in Refs. 9 and 10 for mitigating the tether transient dynamics into the simulations of payload capture and release.

\section{Conclusions}

A spinning tethered system for transfers from low Earth orbit to geostationary orbit combines the efficiency of electrical propulsion (high specific impulse) and the delivery speed of a chemical system. A two-stage tether system of reasonable size and relatively small mass can be devised for transferring payloads with a mass up to $4000 \mathrm{~kg}$ to geostationary orbit with the circularization velocity increment provided by the kick motor of the payload. The transfer time for the two-stage tether system is $16: 50 \mathrm{hr}$ :min which is comparable to the typical 5:30 hr:min transfer time of a chemical upper stage. The study shows that a two-stage tether system is more competitive, on a mass basis, than a chemical-propellant upper stage after two orbital transfers.

The orbital design of the system makes use of resonant orbits to provide periodic conjunctions (or visits) between the $1^{\text {st }}$ and $2^{\text {nd }}$ stage and multiple opportunities for capture of the payload in case of miscapture by the $2^{\text {nd }}$ stage. The ideal transfer frequency of a two-stage system is determined by the periodic realignment (dependent upon the Earth oblateness) of the two stages apsidal lines. The ideal maximum transfer rate consistent with the orbital design derived in this paper is once every 72 days or 5 transfers per year. The transfer rate of a single-stage system is not determined by apsidal realignment but rather by the time required for efficiently reboosting the stage. A singlestage system is three times heavier than a two-stage system with present-day tether materials but it should be considered in the future as tether material characteristics improve. 


\section{Acknowledgements}

This work was supported by NASA Marshall Space Flight Center through NASA Grant NAG8-1303. The authors would like to thank for their contributions Heather Dionne, Elisabeth Fleming, William Klus, Karmel Herring, Elton Suggs and Lawrence Walker of the Boeing Defense and Space Group and Constance Carrington and Linda Vestal of NASA Marshall Space Flight Center.

\section{References}

${ }^{1}$ Bangham, M.E., Lorenzini, E. and Vestal, L., "Tether Transport System Study." NASA/TP-1998-206959, March 1998.

${ }^{2}$ Fuller, P.N., "Commercial Spacecraft Mission Model Update." Report of the COMSTAC Technology \& Innovation Working Group, US Department of Transportation, Washington, D.C., July 1995.

${ }^{3}$ Bekey, I. and Penzo, P., "Tether Propulsion.” Aerospace America, Vol. 24, No. 7, 1986, pp. 40-43.

${ }^{4}$ Carroll, J.A., "Guidebook for Analysis of Tether Applications." NASA Report, NASA-CR-178904, March 1985.

${ }^{5}$ Hoyt, R.P., "Tether System for Exchanging Payloads between the International Space Station and the Lunar Surface." Tether Technology Interchange Meeting, NASA/CP-1998-206900, January 1998, pp. 271-284.

${ }^{6}$ Moravec, H., "A Non-Synchronous Orbital Skyhook." The Journal of the Astronautical Sciences, Vol. 25, No. 4, 1977, pp. 307-322.

${ }^{7}$ Puig-Suari, J., Longuski, J.M. and Tragesser, S.G., "A Tether Sling for Lunar and Interplanetary Exploration." Proceedings of the IAA International Conference on lowcost Planetary Missions, Laurel, MD, April 1994, Paper IAA-L-0701P.

${ }^{8}$ Oldson, J. and Carroll J.A., "Potential Launch Cost Savings of a Tether Transport Facility." Proceedings of the 31st AIAA/ASME/SAE/ASEE Joint Propulsion Conference and Exhibit, San Diego, CA, July 1995, Paper AIAA 95-2895.

${ }^{9}$ Colombo, G., "Orbital Transfer and Release of Tethered Payloads." NASA Report, NASA-CR-170779, March 1983.

${ }^{10}$ Carroll, J.A., "Preliminary Design of a $1 \mathrm{~km} / \mathrm{s}$ Tether Transport Facility." Final Report on NASA contract NASW-4461, March 1991.

${ }^{11}$ Wertz, J.R. and Larson, W.J., "Space Mission Analysis and Design." Kluwer Academic Publishers, 1991, p. 614. 